\title{
Research Paper: The Mediating Role of Rumination on Parenting Style, Childhood Trauma, and Adulthood Depression
}

\author{
Ali Bahari ${ }^{1}$, Mahsa Akbarian Firoozabadi ${ }^{{ }^{*}}$, , Shahram Mohammadkhani $^{1}$
}

1. Department of clinical psychology, Faculty of Psychology and Education, Kharazmi university, Tehran, Iran.

$\begin{gathered}\text { Use yur devic to scan } \\ \text { and read the article online }\end{gathered}$
$\begin{aligned} & \text { enting Style, Childhood Trauma, and Adulthood Depression. Journal of Practice in Clinical Psychology, 7(3), 197-206. http:// } \\ & \text { dx.doi.org/10.32598/jpcp.7.3.197 }\end{aligned}$
d colhttp://dx.doi.org/10.32598/jpcp.7.3.197

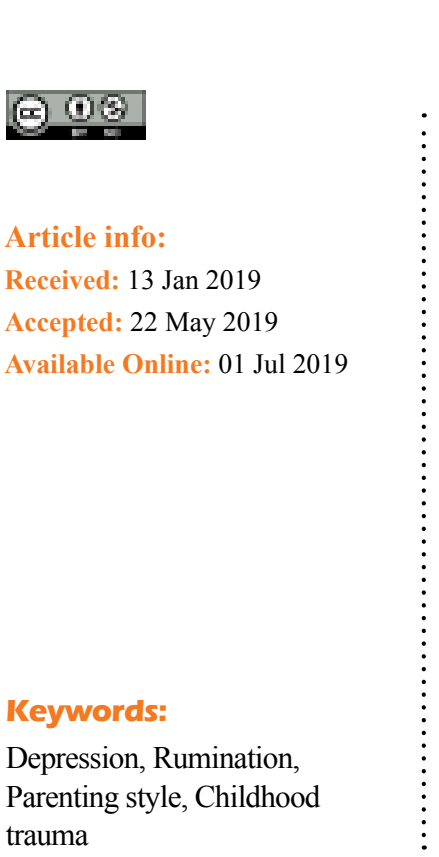

\section{ABSTRACT}

Objective: The present study aimed to determine the roles of maternal care and overprotection. We also explored how they are combined to develop rumination as well as various childhood traumas and parenting styles as the risk factors for depression.

Methods: This was a retrospective study with a causal-comparative design. In total, 175 students with the Mean \pm SD age of $21 \pm 2.75$ years (age range: 18 - 35 years) affiliated to Alborz Medical University, Tehran University, and Kharazmi University have been selected using purposive sampling method. They completed the 2nd version of Beck Depression Inventory, Ruminative Response Scale, Parental Bonding Instrument, and Childhood Trauma Questionnaire. The obtained data were analyzed by the Analysis of Variance (ANOVA), path analysis, mediation analysis, and correlation calculations, in SPSS and AMOS.

Results: The mediating role of rumination in respect of parenting styles $(\mathrm{P}<0.02)$ and depression $(\mathrm{P}<0.001)$ was statistically significant. Moreover, parenting styles and childhood traumas, and their interaction may lead to the development of rumination and depression $(\mathrm{P}<0.001)$ The pathways of the effects were different; limited maternal care plays an indirect role in this process. This indicates that it will lead to depression and rumination only if emotional abuse is experienced in childhood. However, overprotection can directly lead to these conditions.

Conclusion: Paying attention to parenting styles, childhood traumas, and their interaction to prevent rumination and depression is important. This is due to the identified direct and indirect effects of parenting behaviors.

\section{* Corresponding Author:}

Mahsa Akbarian Firoozabadi, MSc.

Address: Department of clinical psychology, Faculty of Psychology and Education, Kharazmi university, Tehran, Iran.

Tel: +98 (919) 4350221

E-mail:akbarianmahsa84@gmail.com 


\section{Highlights}

- The mediating role of rumination between parenting styles and depression has been proven.

- Both parenting styles and childhood traumas lead to rumination and depression.

- Low mother's care plays an indirect role in this process.

\section{Plain Language Summary}

Depression is a psychological disorder with different symptoms such as rumination which is defined by recurrent passive thoughts. Many factors can lead to these kinds of ideas and depression. Rumination can be formed during childhood by the way parents treat their children and also by the traumatic events a child faces. In this study, we tried to investigate the relationships among these factors. The results indicate that all factors are related together. In other words, parental behaviors can lead to depression directly and indirectly. Overprotection plays a direct role in this process, but the effect of low maternal care is indirect. As a result, childhood period can be crucial and provide the background for depression development when all these factors interact. Parents' behaviors and their effects, which provoke emotional or cognitive reactions in children can lead to depression in their adulthood.

\section{Introduction}

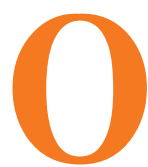

ver the past two decades, rumination has been considered important in comprehending the development and persistence of depression (Krause et al., 2017). It is defined as a set of recurrent passive thoughts (Clark \& Beck, 2018), and creates mechanisms, leading to depression (Michl, McLaughlin, Shepherd, \& NolenHoeksema, 2013). Although the relation of rumination and depression is well studied, little is known about the development of this structure (Schweizer, Olino, Dyson, Laptook, \& Klein, 2017). Response styles theory of depression states that rumination, as a cognitive style, is formed during childhood. Studies have considered factors like parenting styles (Chow \& Lo, 2017; Williams, Harfmann, Ingram, Hagan, \& Kramer, 2015), and childhood traumas (Kim, Jin, Jung, Hahn, \& Lee, 2017), as effective environmental phenomena, leading to the development of rumination.

Manfredi et al., (2011) argued overprotection is the only important factor predicting the development of rumination and worry. However, Williams et al., (2015) suggested maternal care levels significantly predict brooding, depression severity, and anxiety symptoms. Low maternal care and high overprotection are associated with the development of anxiety and depression through the mediating role of dysfunctional cognitions (Acharya \& Relojo, 2017).
Childhood abuse or trauma is another developmental antecedent of rumination and depression that has received significant empirical and theoretical attention. Maltreated children often experience a lack of control over their lives. Therefore, it can be another risk factor for developing a ruminative response style (Kim et al., 2017). Numerous studies have supported the relationship between childhood maltreatment and adulthood depression, with most of them focusing on sexual, physical, and emotional maltreatment and abuse (O'Neill et al., 2018). Gibb et al., (2001) supported the mediating role of negative cognitive styles between childhood emotional maltreatment and depression episodes in late adolescence and early youth. Additionally, childhood emotional abuse, as a partial mediator between childhood emotional abuse and depression, is related to rumination (O’Mahen, Karl, Moberly, \& Fedock, 2015).

Parenting styles and childhood traumas are related to rumination and depression (Chow \& Lo, 2017; Kim et al., 2017); however, they have not been simultaneously studied to unfold the related details. Furthermore, it is not specified which trauma types (physical, sexual, emotional) (Spasojević \& Alloy, 2002) have a greater effect on the formation of rumination. In addition, there are diverse results about the effects of overprotection and care in this regard (Manfredi et al., 2011; O'Mahen et al., 2015; Williams et al., 2015). Therefore, it is necessary to clarify the role of these factors in inducing rumination and the concurrence of childhood traumas and parenting styles. The discriminative feature of this study was investigating the concurrence of perceived parenting 
styles and childhood traumas, as well as the influences of various traumas on such relationship. We have hypothesized that care and overprotection are associated with rumination (Manfredi et al., 2011; Williams et al., 2015); childhood trauma and its scales are related to rumination (Kim et al., 2017); and rumination plays a mediating role between parenting styles and depression symptoms (Gate et al., 2013).

\section{Methods}

This was a retrospective study with a causal-comparative design. The target population included the students of Kharazmi University of Tehran, Tehran University, and Alborz University of Medical Sciences in the first semester of 2017 . The sample size was estimated as 195 by the offered formulas in multiple linear regression studies (Hsieh, Bloch, \& Larsen, 1998). Using a purposive sampling method, the data of 205 subjects were collected from the faculties of technology, science, literature, and medicine. Due to incomplete response patterns, 30 subjects were excluded from the study. The final sample contained 175 students ( $42.3 \%$ males), aged $18-35$ years (Mean \pm SD age: $21 \pm 2.75$ years).

Two researchers repeatedly attended college classes and explained the research to the students. The volunteer participants responded to the inventories after a short interview, comprising inclusion (growing up by biological parents, no history of mental and physical illnesses) and exclusion (current self-reported depression) criteria. Informed consent was obtained from the subjects. All ethical rights have been considered. The subjects' educational level were as follows: BS: $88 \%$., MA: 10.9\%, $\mathrm{MD}$ and $\mathrm{PhD}: 1.1 \%$. Moreover, 90.3\% were single, and $87.4 \%$ of them were monolingual. Each subject answered 4 questionnaires. Alpha and power were respectively calculated as 0.05 and 0.90 . A hypothetical model was assumed where rumination scales (brooding and reflection) played a mediating role between maternal factors (care and overprotection) and depression symptoms. It included 5 variables and 8 covariates.

The correlation coefficients between these variables obtained from the previous studies were as follows: -0.31 , $0.26,0.44$, and 0.42 , respectively between brooding and maternal care, maternal overprotection, depression symptoms, and reflection; $-0.15,0.16$, and, 0.41 between reflection and maternal care, maternal overprotection, and depression symptoms, and 0.34 between maternal care and maternal overprotection (Treynor, Gonzalez, \& Nolen-Hoeksema, 2003; Williams et al., 2015). The obtained data were analyzed by the Analysis of Variance
(ANOVA), path analysis, mediation analysis, and correlation calculations in SPSS and AMOS.

\section{Instruments}

Beck Depression Inventory-II: BDI-II was developed by Beck, Steer, \& Brown (1996). It consists of 21 items evaluating depression symptoms in 4 options, ranging from 0 to 3 (Beck et al., 1996). BDI's internal consistency estimates yielded a mean coefficient alpha of 0.86 for psychiatric patients and 0.81 for non-psychiatric subjects (Beck, Steer, \& Carbin, 1988). The internal consistency (Cronbach's alpha coefficient) and test-retest reliability of its Persian version were reported equal to 0.87 and 0.74, respectively (Ghassemzadeh, Mojtabai, Karamghadiri, \& Ebrahimkhani, 2005).

Ruminative Response Scale (RRS): It is a subset of the Nolen-Hoeksema and Morrow (1991) Response Styles self-reporting questionnaire with 22 items scored on a Likert-type scale (1 to 4). Its Cronbach's alpha and retest reliability coefficients were 0.9 and 0.67 , respectively (Yook, Kim, Suh, \& Lee, 2010). Its obtained Cronbach's alpha coefficient in the present study was calculated as 0.91 . The internal consistency of brooding and reflection subscales of the Persian version of RRS were reported to be 0.79 and 0.69 , respectively. Moreover, the Cronbach's alpha coefficient for these subscales were 0.77 and 0.68, respectively (Mohammadkhani, Purmand, \& Hassanabadi, 2013).

Parental Bonding Instrument (PBI). It was developed by Parker, Tupling, \& Brown (1979). It is a 25-item self-reporting scale measuring the parenting styles experienced by people in their first 16 years of life. Parents are judged on a 4-point scale, and two factors (care and overprotection) are examined for both parents. It has to be separately completed by mother and father. Parenting styles are dividing into 4 categories, as follows: high care-low protection or optimal parenting; high care-high protection or affectionate constraint; low care-low protection or neglectful parenting; and low care-high protection or affectionless control. The cutoff points of care and overprotection factors were obtained as 27 and 13.5, respectively.

The internal reliability coefficients of the 'care' and 'overprotection' dimensions were reported as 0.85 and 0.68, respectively (Parker et al., 1979). The factor structure and psychometric properties of the Persian version of PBI were also examined. The Cronbach's alpha coefficients were all high, ranging from 0.79 to 0.88 for the maternal and the paternal forms (Behzadi \& Parker, 
2015). Cronbach's alpha coefficient of maternal care and overprotection were 0.89 and 0.76 , respectively in this study. Considering recent studies about parenting styles and rumination emphasizing on mother's behaviors (Gate et al., 2013; Psychogiou et al., 2017; Williams et al., 2015), in this study, PBI was only used for the mothers.

Childhood Trauma Questionnaire-Short Form (CTQ$\mathrm{SF}$ ). It has 5 clinical scales, including emotional abuse, physical abuse, sexual abuse, emotional neglect, physical neglect as well as a total score, indicating general maltreatment. The reliabilities of the various scales of CTQ have been reported to be 0.79 to 0.94 by test-retest and the Cronbach's alpha coefficient methods. CTQ-SF consists of 5 items per clinical scale, 3 denial assessment items, and a total of 28 phrases (Bernstein \& Fink, 1998). The validity and reliability of CTQ-SF (Persian version) have been reported by prior research. The testretest reliability coefficient of its Persian version was equal to 0.90 , and the mean score of internal consistency reliability coefficients for the subscales have been reported as 0.79 (Garrusi \& Nakhaee, 2009). The Cronbach's alphas coefficients obtained in the present study were as follows: total maltreatment: 0.91; emotional abuse: 0.87; physical abuse: 0.96; sexual abuse: 0.91; emotional neglect: 0.68 , and physical neglect: 0.68 .

\section{Results}

Descriptive statistics are demonstrated in Table 1. The correlations between different variables are presented in Table 2. One-way ANOVA results revealed a significant difference in the total rumination score among those with different parenting styles of their parents, $\left(\mathrm{F}_{1.137}=3.910\right.$, $\mathrm{P}<0.01)$. Furthermore, this difference was statistically significant for brooding subscale, $\left(\mathrm{F}_{1.137}=2.946, \mathrm{P}<0.34\right)$, but not for reflection, $\left(\mathrm{F}_{1.137}=0.904, \mathrm{P}<0.441\right)$. Bonferroni post-hoc test results suggested a significant difference between affectionless control and optimal parenting in the total rumination score, $(\mathrm{P}<0.006)$, and brooding $(\mathrm{P}<0.003)$.

To understand which of the rumination and parenting factors may have the mediating role, multiple regression analyses were conducted. First, we examined the mediating role of rumination's scales between overprotection and depression symptoms. Then, the mediating role of these scales was examined between care and depression symptoms. The mediation analyses results are listed in Table 3. These analyses were conducted using Bootstrapping method (MacKinnon, Lockwood, \& Williams, 2004; Preacher \& Hayes, 2004). Indirect effects, with $95 \% \mathrm{Cl}$, were investigated based on 5000 bootstrap

Table 1. descriptive statistics of study scales by gender

\begin{tabular}{|c|c|c|c|}
\hline \multirow{2}{*}{ Measure } & \multicolumn{3}{|c|}{ Mean \pm SD } \\
\hline & Female & Male & Total \\
\hline Beck depression inventory & $10.39 \pm 7.33$ & $11.64 \pm 7.64$ & $10.91 \pm 7.46$ \\
\hline Rumination-total & $45.23 \pm 13.58$ & $47.89 \pm 10.70$ & $46.35 \pm 12.48$ \\
\hline Rumination-brooding & $10.97 \pm 4.41$ & $11.26 \pm 3.14$ & $11.09 \pm 3.91$ \\
\hline Rumination-reflection & $10.12 \pm 3.45$ & $10.81 \pm 3.43$ & $10.41 \pm 3.45$ \\
\hline Maternal care & $26.76 \pm 7.46$ & $25.96 \pm 6.25$ & $26.42 \pm 6.9$ \\
\hline Maternal overprotection & $17.01 \pm 6.39$ & $16.94 \pm 6.54$ & $16.98 \pm 6.43$ \\
\hline Childhood trauma-total & $36.60 \pm 16.04$ & $37.59 \pm 11.52$ & $37.00 \pm 14.28$ \\
\hline Emotional abuse & $7.48 \pm 4.18$ & $7.84 \pm 3.72$ & $7.60 \pm 3.90$ \\
\hline Physical abuse & $6.40 \pm 4.24$ & $6.65 \pm 3.44$ & $6.50 \pm 3.90$ \\
\hline Sexual abuse & $6.17 \pm 3.46$ & $5.86 \pm 1.73$ & $6.00 \pm 2.80$ \\
\hline Emotional neglect & $8.36 \pm 4.22$ & $9.20 \pm 3.93$ & $8.90 \pm 4.70$ \\
\hline Physical neglect & $6.73 \pm 2.93$ & $7.44 \pm 2.91$ & $7.00 \pm 2.90$ \\
\hline
\end{tabular}


Table 2. Calculated correlations between used scales

\begin{tabular}{|c|c|c|c|c|c|c|c|c|c|c|c|c|}
\hline Scale & BDI & RT & RB & RR & MC & MO & CTT & EA & PA & SA & EN & PN \\
\hline BDI & 1.00 & & & & & & & & & & & \\
\hline RT & $0.70^{* * *}$ & 1.00 & & & & & & & & & & \\
\hline $\mathrm{RB}$ & $0.61^{* * *}$ & $0.86^{* * *}$ & 1.00 & & & & & & & & & \\
\hline RR & $0.43^{* * *}$ & $0.75^{* * *}$ & $0.46^{* * *}$ & 1.00 & & & & & & & & \\
\hline$M C$ & $-0.31^{* * *}$ & $-0.33^{* * *}$ & $-0.28^{* * *}$ & $-0.19^{* *}$ & 1.00 & & & & & & & \\
\hline MO & $0.23^{* *}$ & $0.23^{* *}$ & $0.30^{* * *}$ & 0.02 & $-0.35^{* * *}$ & 1.00 & & & & & & \\
\hline CTT & $0.41^{* * *}$ & $0.37^{* * *}$ & $0.36^{* * *}$ & $0.16^{*}$ & $-0.69^{* * *}$ & $0.34^{* * *}$ & 1.00 & & & & & \\
\hline EA & $0.45^{* * *}$ & $0.37^{* * *}$ & $0.37^{* * *}$ & $0.16^{*}$ & $-0.65^{* * *}$ & $0.40^{* * *}$ & $0.87^{* * *}$ & 1.00 & & & & \\
\hline PA & $0.34^{* * *}$ & $0.32 * * *$ & $0.33^{* * *}$ & 0.12 & $-0.46^{* * *}$ & $0.34^{* * *}$ & $0.86^{* * *}$ & $0.75^{* * *}$ & 1.00 & & & \\
\hline SA & $0.27^{* * *}$ & $0.27^{* * *}$ & $0.34^{* * *}$ & 0.08 & $-0.42^{* * *}$ & $0.18^{*}$ & $0.76^{* * *}$ & $0.59^{* * *}$ & $0.70^{* * *}$ & 1.00 & & \\
\hline EN & $0.35^{* * *}$ & $0.36^{* * *}$ & $0.31^{* * *}$ & $0.22^{* *}$ & $-0.73^{* * *}$ & $0.27^{* * *}$ & $0.78^{* * *}$ & $0.69^{* * *}$ & $0.54^{* * *}$ & $0.40^{* * *}$ & 1.00 & \\
\hline PN & $0.25^{* * *}$ & $0.19^{*}$ & $0.17^{*}$ & 0.07 & $-0.49^{* * *}$ & 0.09 & $0.76^{* * *}$ & $0.53^{* * *}$ & $0.53^{* * *}$ & $0.52^{* * *}$ & $0.51^{* * *}$ & 1.00 \\
\hline
\end{tabular}

${ }^{*} \mathrm{P}<0.05 ;{ }^{* *} \mathrm{P}<0.01 ;{ }^{* *} \mathrm{P}<0.001$

BDI: Beck Depression Inventory; RT: Rumination-Total; RB: Rumination-Brooding; RR: Rumination-Reflection; MC: Maternal Care; MO: Maternal Overprotection; CTT: Childhood Trauma-Total; EA: Emotional Abuse; PA: Physical Abuse; SA: Sexual Abuse; EN: Emotional Neglect; PN: Physical Neglect

samples (Preacher \& Hayes, 2004). The significance of each mediation model is summarized in Table 4

The final model describes how childhood traumas and parenting styles were combined to induce rumination and depression symptoms (Figure 1). This model was evaluated by the Chi-squared test, Comparative Fit Index (CFI), Normed Fit Index (NFI), Root Mean Square Error of Approximation (RMSEA) in SPSS and AMOS. Path coefficients were measured at 0.05 significant level. The chi-squared test result was not statistically signifi- cant, $\mathrm{x}(\mathrm{df}=3, \mathrm{n}=175)=0.335, \mathrm{P}<0.953$; thus, there was no difference between the suggested model and the gathered data, and the observed data were consistent with this model. Good fit indices are presented in Table 5 , indicating the fitness of the model with the obtained data. All the path coefficients were statistically significant $(\mathrm{P}<0.05)$. This model demonstrates that both of the parenting scales (care and overprotection) affect the development of ruminative brooding.

Table 3. Results of mediation analyses

\begin{tabular}{|c|c|c|c|c|c|c|c|c|}
\hline \multirow[b]{2}{*}{ IV } & \multirow[b]{2}{*}{ MV } & \multirow[b]{2}{*}{ DV } & \multirow{2}{*}{$\begin{array}{l}\text { Effect of } \\
\text { IV on MV } \\
\text { (a) }\end{array}$} & \multirow{2}{*}{$\begin{array}{l}\text { Effect of } \\
\text { MV on DV } \\
\text { (b) }\end{array}$} & \multicolumn{2}{|c|}{ Direct Effect MV } & \multirow[b]{2}{*}{ Indirect Effect $(a * b)$} & \multirow[b]{2}{*}{ Total } \\
\hline & & & & & $\begin{array}{l}\text { Before Control- } \\
\text { ling (c) }\end{array}$ & $\begin{array}{l}\text { After Control- } \\
\text { ling (ć) }\end{array}$ & & \\
\hline MO & $\mathrm{RB}$ & $\mathrm{BDI}$ & $0.30^{* * *}$ & $0.59^{* * *}$ & $0.23^{* *}$ & 0.06 & $0.20(0.33<\mathrm{Cl}<0.96)$ & 0.26 \\
\hline MC & $\begin{array}{l}\mathrm{RB} \\
\mathrm{RR}\end{array}$ & $\mathrm{BDI}$ & $\begin{array}{l}-0.21^{* * *} \\
-0.19^{* *}\end{array}$ & $\begin{array}{l}0.48^{* * *} \\
0.18^{* *}\end{array}$ & $-0.31^{* * *}$ & $-0.14^{*}$ & $-0.18(-0.32<\mathrm{Cl}<-0.07)$ & -0.32 \\
\hline
\end{tabular}


Table 4. Summary of mediating models

\begin{tabular}{|c|c|c|}
\hline Model & 1 & 2 \\
\hline $\mathrm{R}^{2}$ Adjusted & 0.36 & 0.40 \\
\hline $\mathrm{F}$ & 50.00 & 0.40 \\
\hline Degrees of freedom & 172.00 & 171.00 \\
\hline Between-group error & 2.00 & 3.00 \\
\hline$P$ & 0.0001 & 0.0001 \\
\hline
\end{tabular}

Table 5. Fitness indices of the model

\begin{tabular}{|c|c|}
\hline Index & $\mathbf{P}$ \\
\hline$x_{3.175}$ & 0.335 \\
\hline CFI & 1.000 \\
\hline $\mathrm{NFI}$ & 0.999 \\
\hline RMSEA & 0.000 \\
\hline
\end{tabular}

Moreover, the effect of care factor is entirely indirect and mediated by emotional abuse; although the effect of overprotection is partially mediated by emotional abuse with a direct main effect. Brooding and emotional abuse are also the predictors of depression symptoms. The effect of emotional abuse is indirect through partial mediating of brooding; however, its main effect is direct (Figure 1).

\section{Discussion}

The present study aimed to clarify the roles of care and overprotection, their combination in the development of rumination, and the simultaneous concurrence of various childhood abuse types along with parenting styles, in the development of depression symptoms. Calculating the correlations suggested that parenting styles and

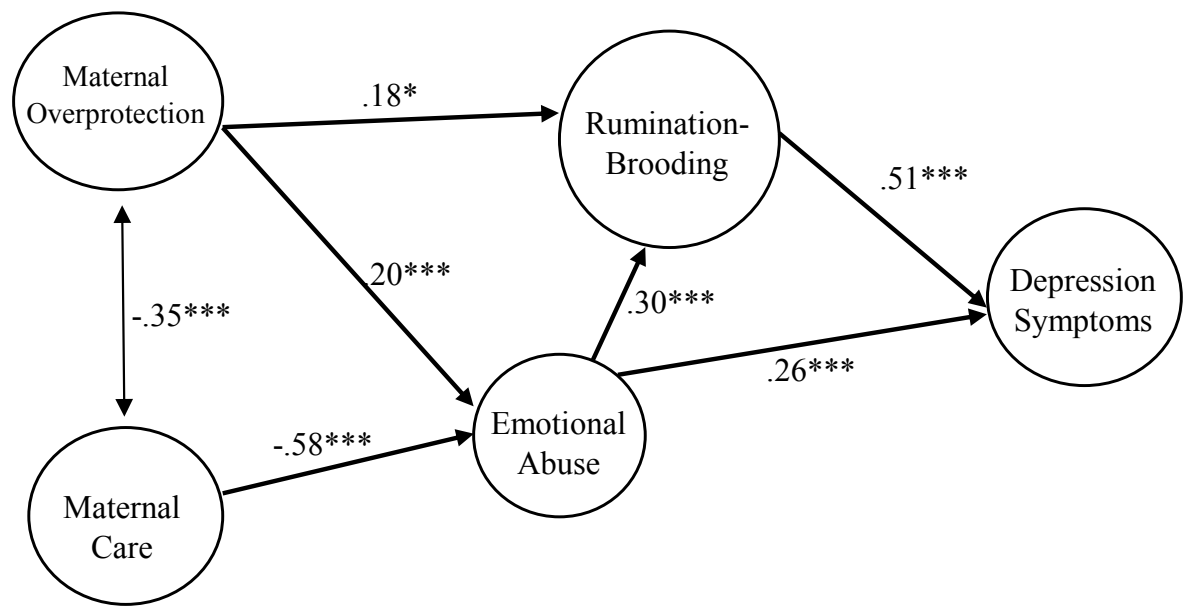

PUANICAL PSYCH LOOY

Figure 1. Structural equatmodel of overprotection, care factors, and ruminative brooding

Standardized path coefficients.

${ }^{*} \mathrm{P}<0.05 ;{ }^{* *} \mathrm{P}<0.01 ;{ }^{* *} \mathrm{P}<0.001$ 
childhood traumas usually affect the development of ruminative brooding, more than reflection. Considering the definition of rumination components (Horwitz, Czyz, Berona, \& King, 2018), brooding is more related to psychological distress and depression.

The difference in the severity of rumination between individuals who were grown up under optimal and affectionless control parenting styles was remarkable and only observed in the brooding scale. This finding is consistent with Johnson, Carr, and Whisman (2015) reporting overprotective parenting style and the negative-submissive expressivity of family during preschool predict rumination in youth. In addition, parenting styles correlated with high overprotection and control are associated with depression (Lay-Yee, Milne, Shackleton, Chang, \& Davis, 2018).

By investigating the mediating variables, consistent with the results of Manfredi et al., (2011), we found brooding completely mediates between mother's overprotection and depression symptoms. Moreover, consistent with the results of Williams et al., (2015), the mediation of rumination components between mother's care and depression symptoms was determined; it is, directly and indirectly, contributed to the development of depression symptoms. Children whose caregivers are hostile and critical may fail to develop adaptive coping strategies (Gate et al., 2013; Schweizer et al., 2017).

Finally, we developed a model describing how parenting styles and childhood traumas combine to induce rumination and depression symptoms (Figure 1). Previous research studies have emphasized on the roles of overprotection (Manfredi et al., 2011), care (Williams et al., 2015), and their combination (McGinn, Cukor, \& Sanderson, 2005) in the development of rumination. Our results supported the simultaneous effects of low care and high overprotection. The new finding is that limited mother's care indirectly induces rumination and depression through the development of emotional abuse; while, overprotection mainly and directly induces the rumination. Therefore, they differently contribute to the development of depression symptoms. Limited maternal care can only induce rumination and depression if it causes the perception of emotional abuse in the child. Thus, the role of child's temperament is very important (Schweizer et al., 2017). The direct effect of overprotection can be reflected in the destruction of child's chances of developing adaptive coping strategies, leading to high self-criticism, low self-efficacy, and passive strategies like rumination.
The main limitations of this study included applying the purposive sampling method, the small sample size, and the exclusive use of questionnaires, restricting the generalization of the obtained results. The present study emphasized on the role of environmental factors, including parent-child interactions, in the formation of dysfunctional coping strategies against psychological distresses. It can be beneficial in identifying vulnerable people to rumination and depression. The collected data suggested two potential parenting behaviors; those directly affecting the development of rumination (overprotective), and those interacting with child's temperament (caring). The obtained results reflect the importance of parental training. Interventions focusing on coping strategies and psychological trainings like problem-solving and active copings can be effective to reduce rumination. It is suggested that the temperamental variables be investigated in future studies to achieve a comprehensive model.

The obtained results suggested that low care and high overprotection significantly affect the development of rumination and depression. Moreover, limited maternal care indirectly influenced this process. This finding indicates that such condition may lead to depression and rumination, only if emotional abuse is experienced in childhood. However, overprotection mainly and directly can lead to these conditions. As a result, parenting styles, childhood traumas, and their interaction can be crucial in preventing rumination and depression.

\section{Ethical Considerations}

\section{Compliance with ethical guidelines}

All ethical principles were considered in this research. Informed consent was obtained from all study participants; they were also assured about the confidentiality of their information. Moreover, they were allowed to discontinue study participation as desired. Some of the obtained results are available to them upon request.

\section{Funding}

This research received no specific grant from funding agencies in the public, commercial, or not-for-profit sectors.

\section{Authors' contributions}

All authors contributed in preparing this article.

\section{Conflict of interest}

The authors declare no conflict of interest. 


\section{References}

Acharya, S., \& Relojo, D. (2017). Examining the role of cognitive distortion and parental bonding in depressive symptoms among male adolescents: A randomised crossover trial. Journal of Innovation in Psychology, Education and Didactics, 21(1) 7-20.

Beck, A. T., Steer, R. A., \& Brown, G. K. (1996). Beck depression inventory-II. San Antonio, 78(2), 490-8. [DOI:10.1037/t00742000]

Beck, A. T., Steer, R. A., \& Carbin, M. G. (1988). Psychometric properties of the Beck Depression Inventory: Twenty-five years of evaluation. Clinical Psychology Review, 8(1), 77-100. [DOI:10.1016/0272-7358(88)90050-5]

Behzadi, B., \& Parker, G. (2015). A Persian version of the parental bonding instrument: Factor structure and psychometric properties. Psychiatry Research, 225(3), 580-7. [DOI:10.1016/j. psychres.2014.11.042] [PMID]

Bernstein, D. P., \& Fink, L. A. (1998). CTQ: Childhood Trauma Questionnaire: A retrospective self-report. San Antonio: The Psychological Corporation.

Chow, K. W., \& Lo, B. C. (2017). Parental factors associated with rumination related metacognitive beliefs in adolescence. Frontiers in Psychology, 8(536):1-10 [DOI:10.3389/fpsyg.2017.00536]

Clark, D. A. (2018). The anxious thoughts workbook: Skills to overcome the unwanted intrusive thoughts that drive anxiety, obsessions, and depression. Oakland: New Harbinger Publications.

Garrusi, B., \& Nakhaee, N. (2009). Validity and reliability of a Persian version of the Childhood Trauma Questionnaire. Psychological Reports, 104(2), 509-16. [DOI:10.2466/PR0.104.2.509516]

Gaté, M. A., Watkins, E. R., Simmons, J. G., Byrne, M. L., Schwartz, O. S., Whittle, S., et al., (2013). Maternal parenting behaviors and adolescent depression: The mediating role of rumination. Journal of Clinical Child $\mathcal{E}$ Adolescent Psychology, 42(3), 348-57. [DOI:10.1080/15374416.2012.755927] [PMID]

Ghassemzadeh, H., Mojtabai, R., Karamghadiri, N., \& Ebrahimkhani, N. (2005). Psychometric properties of a Persian $\square$ language version of the Beck Depression Inventory $\square$ Second edition: BDI $\square$ II $\square$ PERSIAN. Depression and Anxiety, 21(4), 185-192. [DOI:10.1002/da.20070] [PMID]

Gibb, B. E., Alloy, L. B., Abramson, L. Y., Rose, D. T., Whitehouse, W. G., Donovan, P., et al., (2001). History of childhood maltreatment, negative cognitive styles, and episodes of depression in adulthood. Cognitive Therapy and Research, 25(4), 425-46. [DOI:10.1023/A:1005586519986]

Horwitz, A. G., Czyz, E. K., Berona, J., \& King, C. A. (2018). Rumination, brooding, and reflection: prospective associations with suicide ideation and suicide attempts. In N. Jones, M. L. Sharp, A. Phillips, Sh. A. M. Stevelink (Eds), Early View (pp 245-321). Hoboken: Wiley. [DOI:10.1111/sltb.12507] [PMID]

Hsieh, F. Y., Bloch, D. A., \& Larsen, M. D. (1998). A simple method of sample size calculation for linear and logistic regression. Statistics in Medicine, 17(14), 1623-34. [DOI:10.1002/ (SICI)1097-0258(19980730)17:143.0.CO;2-S]

Johnson, D. P., Carr, F. A., \& Whisman, M. A. (2015). Inter-parental conflict and rumination. International Journal of Cognitive Therapy, 8(1), 1-10. [DOI:10.1521/ijct.2015.8.1.1]
Kim, J. S., Jin, M. J., Jung, W., Hahn, S. W., \& Lee, S. H. (2017). Rumination as a mediator between childhood trauma and adulthood depression/anxiety in non-clinical participants. Frontiers in Psychology, 8, 1597. [DOI:10.3389/fpsyg.2017.01597] [PMID] [PMCID]

Krause, E. D., Vélez, C. E., Woo, R., Hoffmann, B., Freres, D. R., Abenavoli, R. M., et al., E. (2018). Rumination, depression, and gender in early adolescence: A longitudinal study of a bidirectional model. The Journal of Early Adolescence, 38(7), $923-$ 46. [DOI:10.1177\%2F0272431617704956]

Lay-Yee, R., Milne, B. J., Shackleton, N., Chang, K., \& Davis, P. (2018). Preventing youth depression: Simulating the impact of parenting interventions. Advances in Life Course Research, 37, 15-22. [DOI:10.1016/j.alcr.2018.05.001]

MacKinnon, D. P., Lockwood, C. M., \& Williams, J. (2004). Confidence limits for the indirect effect: Distribution of the product and resampling methods. Multivariate Behavioral Research 39(1), 99-128. [DOI:10.1207/s15327906mbr3901_4] [PMID] [PMCID]

Manfredi, C., Caselli, G., Rovetto, F., Rebecchi, D., Ruggiero, G. M., Sassaroli, S., et al., (2011). Temperament and parental styles as predictors of ruminative brooding and worry. Personality and Individual Differences, 50(2), 186-91. [DOI:10.1016/j. paid.2010.09.023]

McGinn, L. K., Cukor, D., \& Sanderson, W. C. (2005). The relationship between parenting style, cognitive style, and anxiety and depression: Does increased early adversity influence symptom severity through the mediating role of cognitive style? Cognitive Therapy and Research, 29(2), 219-42. [DOI:10.1007/s10608-005-3166-1]

Michl, L. C., McLaughlin, K. A., Shepherd, K., \& Nolen-Hoeksema, S. (2013). Rumination as a mechanism linking stressful life events to symptoms of depression and anxiety: Longitudinal evidence in early adolescents and adults. Journal of Abnormal Psychology, 122(2), 339-52. [DOI:10.1037/a0031994] [PMID] [PMCID]

Mohammadkhani, S., Purmand, N. S., \& Hassanabadi, H. (2013) An empirical test of a metacognitive model of rumination and depression in non-clinical population. Modern Psychological Research, 8(30), 183-204.

Nolen-Hoeksema, S., \& Morrow, J. (1991). A prospective study of depression and posttraumatic stress symptoms after a natural disaster: The 1989 Loma Prieta earthquake. Journal of Personality and Social Psychology, 61(1), 115-21. [DOI:10.1037/00223514.61.1.115] [PMID]

O'Mahen, H. A., Karl, A., Moberly, N., \& Fedock, G. (2015). The association between childhood maltreatment and emotion regulation: two different mechanisms contributing to depression? Journal of Affective Disorders, 174, 287-95. [DOI:10.1016/j. jad.2014.11.028] [PMID]

O'Neill, A., Beck, K., Chae, D., Dyer, T., He, X., \& Lee, S. (2018) The pathway from childhood maltreatment to adulthood obesity: The role of mediation by adolescent depressive symptoms and BMI. Journal of Adolescence, 67, 22-30. [DOI:10.1016/j. adolescence.2018.05.010] [PMID]

Parker, G., Tupling, H., \& Brown, L. B. (1979). A parental bonding instrument. British Journal of Medical Psychology, 52(1), 1-10. [DOI:10.1111/j.2044-8341.1979.tb02487.x] 
Preacher, K. J., \& Hayes, A. F. (2004). SPSS and SAS procedures for estimating indirect effects in simple mediation models. $\mathrm{Be}$ havior Research Methods, Instruments, \& Computers, 36(4), 71731. [DOI:10.3758/BF03206553]

Psychogiou, L., Moberly, N. J., Parry, E., Russell, A. E., Nath, S., \& Kallitsoglou, A. (2017). Does fathers' and mothers' rumination predict emotional symptoms in their children? British Journal of Clinical Psychology, 56(4), 431-42. [DOI:10.1111/ bjc.12148] [PMID]

Schweizer, T. H., Olino, T. M., Dyson, M. W., Laptook, R. S., \& Klein, D. N. (2018). Developmental origins of rumination in middle childhood: The roles of early temperament and positive parenting. Journal of Clinical Child \& Adolescent Psychology, 47(sup.1), S409-20. [DOI:10.1080/15374416.2017.1359787 ] [PMID] [PMCID]

Spasojević, J., \& Alloy, L. B. (2002). Who becomes a depressive ruminator? Developmental antecedents of ruminative response style. Journal of Cognitive Psychotherapy, 16(4), 405-19. [DOI:10.1891/jcop.16.4.405.52529]

Treynor, W., Gonzalez, R., \& Nolen-Hoeksema, S. (2003). Rumination reconsidered: A psychometric analysis. Cognitive Therapy and Research, 27(3), 247-59. [DOI:10.1023/A:1023910315561]

Williams, C. L., Harfmann, E. J., Ingram, R. E., Hagan, K. E., \& Kramer, N. M. (2015). Specificity of parental bonding and rumination in depressive and anxious emotional distress. Personality and Individual Differences, 79, 157-61. [DOI:10.1016/j. paid.2015.01.055]

Yook, K., Kim, K. H., Suh, S. Y., \& Lee, K. S. (2010). Intolerance of uncertainty, worry, and rumination in major depressive disorder and generalized anxiety disorder. Journal of Anxiety Disorders, 24(6), 623-8. [DOI:10.1016/j.janxdis.2010.04.003] [PMID] 
This Page Intentionally Left Blank 